\section{OS DESAFIOS DO ESTÁGIO CURRICULAR SUPERVISIONADO EM EDUCAÇÃO FÍSICA NA PARCERIA ENTRE UNIVERSIDADE E ESCOLA}

\author{
THE CHALLENGES OF SUPERVISED PHYSICAL EDUCATION CURRICULAR \\ PRACTICUM IN THE PARTNERSHIP BETWEEN UNIVERSITY AND SCHOOL
}

LOS DESAFÍOS DE LA PRÁCTICA PROFESIONAL PEDAGÓGICA SUPERVISADA EN EDUCACIÓN FÍSICA EN LA COLABORACIÓN ENTRE UNIVERSIDAD Y ESCUELA.

Dijnane Fernanda Vedovatto Iza*, Samuel de Souza Neto **
Palavras-chave

Docentes.

Currículo.

Estágios.

Universidades.

Keywords

Faculty,

Curricular Practicum.

Universities.

Palabras clave

Docentes.

Currículo.

Pasantías.

Universidades.
Resumo: Esta pesquisa teve como objetivo compreender os processos de parceria entre escolas e universidade nos estágios curriculares supervisionados em Educação Física. Optou-se pela pesquisa qualitativa, estudo de caso, utilizando como técnicas a entrevista narrativa com sete participantes e a análise de conteúdo. Os dados evidenciaram contradições desse processo no modelo de estágio adotado em que há distanciamento entre as instituições. $O$ desafio está em sair de um modelo de formação centrado na universidade para um modelo que contemple a escola e a universidade como lugares de formação.

Abstract: This study aimed at understanding the processes of partnership between schools and universities in Physical Education's supervised curricular practicum. The approach was qualitative research and case study, using narrative interview with seven subjects as well as content analysis. The results showed contradictions in the process, since the institutions are distant in the model of practicum adopted. The challenge lies in abandoning a model that sees the university as the center of the process and move towards a model that includes schools and universities as educational places.

Resumen: Este estudio tuvo como objetivo central comprender los lazos que se constituyen entre las escuelas y la Universidad en las prácticas pedagógicas supervisadas en educación física. El enfoque investigativo utilizado fue el cualitativo y el tipo de investigación el estudio de caso. Las técnicas de recolección de información fueron el análisis de contenido, la narrativa y la entrevista en profundidad y la unidad de trabajo estuvo compuesta por siete personas. Los resultados reflejan que existen contradicciones, ya que el proceso desvela un alejamiento entre las instituciones. El desafío que promueve este estudio anuncia que se debe incursionar en un modelo que no vea a la Universidad como el centro de dicho proceso, sino un modelo que contemple la escuela y la Universidad como escenarios de formación.
* Universidade Federal de São Carlos. São Carlos, SP, Brasil. E-mail: dijnane@gmail.com

** Universidade Estadual Paulista Julio de Mesquita Filho. Rio Claro, SP, Brasil.

E-mail: samuelsn@rc.unesp.br

Recebido em: 05-04-2014 Aprovado em: 25-08-2014 (c) (i) () Licence 


\section{INTRODUÇÃO}

Este trabalho trata da parceria entre as escolas públicas e a universidade, no que diz respeito aos Estágios Curriculares em Educação Física, tendo como perspectiva que o modelo curricular de formação (BORGES, 2008) influencia esse processo, podendo ser determinante. Parte-se do pressuposto de que o senso comum entende a relação entre universidade e escola como algo simples; ser professor não exige muito em termos de formação, podendo trazer, subjacente a essa compreensão, aforismos como: os que não sabem fazer vão ensinar e os que não sabem ensinar vão dar aula de Educação Física; na prática, os professores se tornam professores, sendo professores.

A literatura da área de formação de professores não compartilha desse senso comum, mas compreende que os saberes profissionais dos professores são diferentes dos conhecimentos universitários (TARDIF, 2000), e que o trabalho docente, aquilo que o professor faz, deveria servir de base para se pensar a formação de professores (CONTRERAS, 2002; TARDIF, 2010). Gauthier et al. (1998) auxiliam nesse exercício, ao perguntarem: o que é necessário para ensinar? Basta ter conhecimento, cultura, talento, experiência, prática etc.? Eles responderão que para ensinar há necessidade de se ter todos esses elementos.

Sobre o assunto, Tardif (2013), ao falar sobre as idades do ensino, aponta que elas estão subordinadas aos paradigmas ou crenças de cada época. Entre os séculos XVII e XIX, predominou a idade do ensino como vocação; ensinar correspondia a uma missão, uma causa, um chamamento; aprendia-se a docência pela observação e convivência com professores experientes. Com a formação das repúblicas, chega-se à fase do registro em carteira, entre os séculos XIX e XX, na idade do ensino como ofício; ensinar levava ao exercício de uma ocupação legalmente constituída, mas que não exigia, necessariamente, uma fundamentação científica da prática pedagógica. Assim, a partir da segunda metade do século XX, iniciou-se nos EUA, nos anos 1980, um movimento pela profissionalização do ensino (HOLMES GROUP, 1986), pensando-o como uma atividade de alto nível na qual se concebe um corpo de conhecimentos que fundamenta a prática docente, chegando-se à idade do ensino como profissão; ensinar passa a ser compreendido como algo importante e fundamentado por um conhecimento de base. Mas, dependendo do país, uma determinada idade pode ser predominante ou haver uma convivência entre elas. De modo que a relação entre universidade e escola é influenciada por esse aspecto.

Neste contexto, seria possível perguntar:

No Brasil, em qual momento se encontra o estágio curricular na relação entre universidade e escola? O estágio curricular ocupa o coração da formação? Há predomínio de uma formação artesanal ou aplicacionista? Qual é o lugar que a escola e a universidade ocupam nesse processo?

Considerando os questionamentos, foi proposto como problema de estudo: quais os elementos na parceria entre Universidade e Escola que nos permitiriam identificar a necessidade de ações mais objetivas entre os participantes e instituições envolvidas com o estágio curricular?

A pesquisa teve como objetivo compreender a parceria entre escolas públicas e universidade no estágio curricular supervisionado de um curso de Educação Física. 


\section{A BASE DE CONHECIMENTOS NO ESTÁGIO CURRICULAR SUPERVISIONADO}

Os estágios curriculares podem ser entendidos como espaços privilegiados de articulação entre teoria e prática, exigindo, por um lado, uma revisão dos formatos, de modo a garantir o tempo e as condições para o contato dos estudantes com os professores das escolas, e por outro "[...] interrogar o grau de interação existente entre as instituições formadoras e as instituições estagiadas, a capacidade de diálogo entre os saberes destas duas instituições e entre os profissionais que nelas atuam" (GIGLIO, 2010, p. 380).

Desse modo, a articulação entre os conhecimentos produzidos nas escolas públicas e na universidade é algo que pode ser promovido por meio dos estágios curriculares, uma vez que possibilita ao futuro professor elementos para compreender a realidade profissional.

Pimenta (2006, p.183) afirma que o "estágio é um dos componentes do currículo do curso de formação de professores. Currículo que é profissionalizante - isto é, prepara para o exercício de uma profissão". Assim, no período do estágio curricular, o estagiário pode apreender elementos constitutivos de uma determinada profissão, sendo importante que ocorra um envolvimento entre o professor (da escola), o estudante estagiário e o professor formador (da universidade), para que o estágio seja efetivamente significativo, pois é 0

[...] componente curricular estruturador da formação docente, numa perspectiva de trabalho coletivo, interdisciplinar e investigativo norteado por princípios voltados para a formação permanente do docente, a aproximação entre os espaços de formação e de exercício profissional e o período destinado aos estágios como processo de investigação pedagógica. (AZEVEDO, 2009, p.32)

Neste dimensionamento, Borges (2008) coloca que no Quebec, Canadá, migrou-se de um modelo acadêmico de formação para um modelo profissional de formação.

Quadro 1 - Modelos de formação curricular

\begin{tabular}{|c|c|c|}
\hline & Modelo acadêmico & Modelo profissional \\
\hline 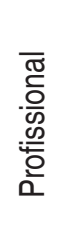 & $\begin{array}{l}\text { Voltado para a formação do profissional que é } \\
\text { tomado como um tecnólogo, um expert, que do- } \\
\text { mina um conjunto de conhecimentos formaliza- } \\
\text { dos e oriundos da pesquisa, a fim de aplicá-los } \\
\text { na prática escolar. }\end{array}$ & $\begin{array}{l}\text { Voltado para a formação do profissional reflexivo, que } \\
\text { produz saberes e é capaz de deliberar sobre sua pró- } \\
\text { pria prática, de objetivá-la, de partilhá-la, de questio- } \\
\text { ná-la e aperfeiçoá-la, melhorando o seu ensino. }\end{array}$ \\
\hline \multirow{4}{*}{ 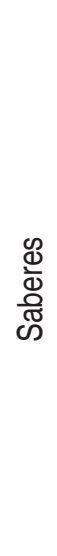 } & Baseado na epistemologia científica. & Baseado na epistemologia da prática. \\
\hline & $\begin{array}{l}\text { Visão unidimensional e disciplinar dos saberes } \\
\text { na base da formação. }\end{array}$ & Visão pluralista dos saberes na base da formação. \\
\hline & $\begin{array}{l}\text { Saberes científicos e curriculares são a referên- } \\
\text { cia para a formação profissional. }\end{array}$ & $\begin{array}{l}\text { Saberes práticos e competências são a referência de } \\
\text { base para a formação profissional. }\end{array}$ \\
\hline & $\begin{array}{l}\text { Pesquisadores e formadores universitários } \\
\text { produzem e controlam os saberes na base da } \\
\text { formação, enquanto os professores aplicam os } \\
\text { saberes na base da formação. }\end{array}$ & $\begin{array}{l}\text { Professores e pesquisadores produzem e controlam } \\
\text { os saberes na base da profissão, o saber da experiên- } \\
\text { cia, os saberes práticos possuem o mesmo estatuto } \\
\text { que os saberes científicos. }\end{array}$ \\
\hline
\end{tabular}




\begin{tabular}{|c|c|c|}
\hline \multirow{6}{*}{ 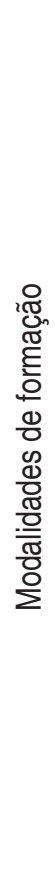 } & Centrada na formação acadêmica. & Centrada na prática. \\
\hline & Estágio não muito longo, no final do curso. & Estágio em alternância ao longo da Formação. \\
\hline & A universidade é o centro da formação. & A escola é o locus central da formação. \\
\hline & $\begin{array}{l}\text { Apesar das idas ao campo (ao meio escolar), é } \\
\text { a universidade que controla todo o processo de } \\
\text { formação. }\end{array}$ & $\begin{array}{l}\text { Ocorre em alternância entre o meio escolar e o meio } \\
\text { de formação na universidade. O processo de forma- } \\
\text { ção é partilhado e, em certa medida, mesmo a avalia- } \\
\text { ção é partilhada entre os atores. }\end{array}$ \\
\hline & $\begin{array}{l}\text { Os atores envolvidos na formação são particu- } \\
\text { larmente os docentes universitários, os profes- } \\
\text { sores que recebem os estagiários se limitam a } \\
\text { dar conselhos, partilhar seu espaço de trabalho } \\
\text { e não participam nem mesmo da avaliação dos } \\
\text { estagiários. }\end{array}$ & $\begin{array}{l}\text { Envolve outros atores que aqueles tradicionalmente } \\
\text { implicados na formação. Além dos professores asso- } \\
\text { ciados (ou tutores, ou mestres de estágio), envolve } \\
\text { diretores, especialistas e técnicos de ensino, super- } \\
\text { visores. }\end{array}$ \\
\hline & $\begin{array}{l}\text { Apoia-se, sobretudo, em dispositivos tradicio- } \\
\text { nais de transmissão de conhecimentos e nota- } \\
\text { damente sobre a ideia de que, dominando um } \\
\text { bom repertório de casos e técnicas, o profissio- } \\
\text { nal é apto a agir em situações reais de ensino. }\end{array}$ & $\begin{array}{l}\text { Envolve dispositivos de desenvolvimento de reflexão } \\
\text { sobre a prática e de tomada de consciência dos sabe- } \\
\text { res. Ancorada em abordagens do tipo por competên- } \\
\text { cias, por problemas, por projetos, clínicas, etc. }\end{array}$ \\
\hline
\end{tabular}

Fonte: Borges (2008, p.161).

Na experiência da Universidade de Montreal (Quebec, Canadá), concebe-se não só a escola como lugar central da formação, mas também uma formação centrada na prática como epistemologia. Portanto, observa-se que o modelo curricular de formação, ao contrário do que se pode pensar, acaba favorecendo a relação entre universidade e escola.

No Brasil, a maioria dos modelos de formação é marcada por uma fragmentação do processo formativo, impingindo a ideia de que é necessário se apropriar da teoria para aplicá-la na prática. Sarti (2009) afirma que as instituições formadoras de professores não mantêm um trabalho articulado com as escolas de educação básica que acolhem os estagiários, apesar das orientações legais a essa respeito. Há uma desarticulação entre as instituições formadoras de professores e a escola. Nessa direção, há a necessidade de promover projetos de estágio, nos quais ocorra a articulação entre ensino, pesquisa e extensão; a formação de professores responsáveis pelos estágios curriculares; a integração entre a universidade e a escola; e as relações entre teoria e prática. Os estágios deveriam servir como condutores das atividades que serão desenvolvidas na escola, vinculadas aos projetos da escola e da universidade (AZEVEDO, 2009).

Outra questão que merece atenção diz respeito a uma cultura da colaboração, pois, independentemente do modelo curricular de formação, algumas propostas de estágio têm a ação colaborativa como princípio de parceria entre universidade e escola, entendendo-as como instituições formadoras (MOURA, 1999).

Borges (2008) também relatou as mudanças no modelo de formação das universidades quebequenses, a partir do movimento de profissionalização do ensino no que se refere à formação docente em Educação Física na Universidade de Montreal. Os estágios passaram a ter uma longa duração (700h), sendo distribuídos ao longo do percurso acadêmico, no qual há períodos de inserção na escola e períodos de formação na universidade, tendo no modelo de alternância entre teoria e prática no processo de formação a sua proposta. Assim, há a inserção gradual dos estudantes no ambiente escolar, indo da familiarização à regência. 
No entanto, a autora coloca que, no âmbito dessa proposição, foi criado na Universidade de Montreal o Centro de Formação Inicial de Mestres. Este centro se tornou responsável pela negociação com as escolas que têm uma estrutura para acolher os estagiários, denominando-as de Escolas Associadas, bem como com os setores de Coordenação de Estágios. Ressalta-se que, para isso, o Ministério da Educação ofereceu suporte financeiro, assim como possibilitou, entre outras coisas, cobrir os custos de liberação dos professores de escola de uma parte de suas atividades, para que pudessem colaborar na formação de futuros professores de Educação Física.

A partir dessas considerações, fomos a campo buscar dados de uma realidade local, visando conhecer melhor as dificuldades enfrentadas pelos participantes desse estudo.

\section{METODOLOGIA}

Optou-se pela pesquisa qualitativa, estudo de caso, tendo como ponto central da investigação o estágio curricular supervisionado no curso de licenciatura em Educação Física de uma universidade pública no interior do estado de São Paulo. Assim, o aspecto da singularidade é o fundamento atrelado aos estudos de caso, de maneira que o "[...] objeto estudado é tratado como único, uma representação singular da realidade que é multidimensional e historicamente situada" (LÜDKE; ANDRÉ, 2001, p.21).

$\mathrm{Na}$ busca dos dados, escolheu-se como técnica de pesquisa a entrevista narrativa, com o objetivo de compreender os elementos constituintes do objeto pesquisado. A entrevista possui caráter interativo, na qual são abordados temas complexos em profundidade. Desse modo, o interesse do pesquisador está pautado no percurso de vida dos entrevistados, visando relacioná-los com as situações presentes (ALVEZ-MAZZOTTI; GEWANDSZNAJDER, 2001), uma vez que os sete participantes/agentes ocupam as duas esferas da relação de parceria.

Nesta compreensão, a entrevista narrativa foi entendida como uma forma de entrevista que possui características próprias, permitindo-nos filtrar os acontecimentos tidos como significativos, bem como a visão que se tem desse processo, com os seguintes sujeitos: a) um professor de estágio curricular da universidade; b) dois professores de Educação Física das escolas; c) duas diretoras de escolas; d) uma coordenadora da área de Educação Física na Diretoria de Ensino; e) uma supervisora responsável pelos estágios na Diretoria de Ensino, sendo todos envolvidos diretamente com os estágios curriculares supervisionados da Educação Física.

No contato com esses participantes, apresentou-se um resumo da proposta de estudo e os procedimentos da entrevista, realizando-a em seguida. As entrevistas foram realizadas individualmente, em local e horário agendados previamente, gravadas em áudio e transcritas integralmente, tendo sido realizadas as mesmas perguntas a todos os participantes do estudo, ressaltando-se que todos os entrevistados assinaram o termo de consentimento livre e esclarecido aprovado pelo comitê de ética em pesquisa1.

O tratamento dos dados foi feito pela técnica da análise de conteúdo das informações obtidas. Os dados foram examinados e organizados em categorias, gerando temas a partir do

$\overline{1 \text { Aprovado pelo Comitê }}$ de Ética do Instituto de Biociências da UNESP/RC - Protocolo nํ7444. 
exame dos relatos e de sua contextualização no estudo. Dessa forma, o estudo foi caracterizado como um método de investigação do conteúdo simbólico das mensagens: na unidade de análise (palavra, sentença, parágrafo ou o texto); na forma de tratar tais unidades e na variação do enfoque da interpretação (LÜDKE; ANDRÉ, 2001).

\section{ESTÁGIO CURRICULAR COMO CONHECIMENTO DA REALIDADE E A REALIDADE DO ESTÁGIO CURRICULAR}

A análise dos dados permitiu a sua organização e compreensão em quatro eixos:

\subsection{Os agentes do processo de estágio na questão da parceria}

Sarti (2012) assinala que as parcerias entre a universidade e as escolas públicas são como portas de acesso que possibilitam a entrada dos estagiários nas escolas, sendo que 0 mesmo foi encontrado neste estudo, pois

O responsável da faculdade vem aqui conversar com a diretora; ela autoriza..., aí os alunos começam a chegar; às vezes eles falam direto com a diretora, e depois comigo, ou às vezes falam diretamente comigo, e a gente começa lá... mas fica assim, a meu critério na verdade, né? Se eu quiser realmente que eles vivenciem as coisas, eu vou propor essa vivência, eu vou trazer eles pra aula, né? Às vezes, alguns me pedem, né? Mas a maioria fica realmente só na observação. (Professor1)

Às vezes tem professor que me liga, a gente conversa antes, às vezes não liga, o aluno vem me procurar, aí depois ele me traz um ofício, se tiver vaga, se tiver condições de atender, né? Ele me traz um ofício, e aí a gente combina, dia, horário, quantas horas de estágio, que sala ele vai, o que é pra ele fazer, é combinado antes. (Diretora 2)

Os apontados também revelam que os primeiros contatos realizados com a escola são feitos pelo professor da disciplina de estágio ou diretamente pelo estagiário focado nos procedimentos burocráticos que fazem parte da rotina de desenvolvimento dos estágios curriculares (BENITES, 2012), suscitando a ideia de colaboração.

\subsection{A Colaboração na Formação Profissional}

Os agentes da escola ressaltaram a necessidade de parcerias com a universidade na perspectiva de se ter um projeto comum.

Seria interessante fazer essa parceria, mas, assim, verdadeira mesmo, sabe? A coisa que vamos fazer... uma parceria pra formar o nosso profissional, tá?, o estagiário vai sair daqui com a nossa teoria e com a prática verdadeira, não assim... vai lá, arruma o estágio, se vira com o professor, se vira com a diretora lá, faz [...] o estágio e eu vou lá assistir sua aula, tá? (Professor2)

Porque eu acho que a escola pública teve uma fase que ela serviu muito de laboratório pra universidade, [...], o pessoal vinha, usufruía, estagiava, escrevia o que queria, e a gente não tinha acesso, não ficava sabendo de nada, de nada, que conclusão chegou? Não tinha esse feedback, então, se for pra não ter feedback, é melhor que nem faça, porque aí também você vai tá usando a escola como laboratório de experiência, e mais nada, então aí já não me interessa, entendeu? Estágio desse tipo não vale a pena pra escola, eu gosto quando tem... tem umas 
meninas da psicologia que estão estagiando, [...], todo final de semestre elas me apresentam um relatório sobre alfabetização, quais crianças elas trabalharam, que dificuldades apresentaram, se evoluiu, se não evoluiu, o que elas sugerem, sabe?

É muito legal. (Diretora 2)

Desse modo, é possível perceber que a parceria é algo almejado como um trabalho conjunto (SARTI, 2012), em que universidade e escola dialoguem coletivamente (MOURA, 1999), mas numa perspectiva profissional (BORGES, 2008).

\subsection{A profissionalização do ensino como enfrentamento}

Neste contexto, o professor responsável pelos estágios expõe as dificuldades dessa parceria, considerando a falta de confiança.

A gente entende como uma parceria, mas muitos deles, ainda, entendem como objeto de verificação, sabe? Eles entendem como alguém sendo fiscalizado, né? O fiscal do estágio, por mais que a gente converse, por mais que a gente mostre que não é mais isso, por mais que a gente converse e mostre tudo que eles poderiam e deveriam fazer em termos de parceiro, porque eu considero eles tanto formadores quanto eu, eu falo isso pra eles, eu mostro isso pra eles, né? (Professor Universidade)

Porém, na visão de uma das diretoras, a questão que se sobressai diz respeito à postura dos estagiários e à falta de orientação por parte do professor da universidade, pois

Outro ponto..., infelizmente..., claro que o professor também não se preocupa..., existem estagiários éticos e estagiários nem tanto. Então aquela coisa, por exemplo, de sair de dentro da sala de aula do professor, falando alguma coisa: Ah! Você viu que ele fez tal coisa assim, assim? E às vezes fala... e às vezes a coisa... sabe, extravasa, vasa, né, é uma coisa chata, e acontece, de vez em quando... acontece, então... eu acho assim... é o que eu tô te falando, existem estagiários e estagiários, professores e professores, da prática, entendeu? (Diretora 2)

Assim, a orientação dos estagiários exige uma postura ética dentro da escola, considerando que isso faz parte de uma deontologia profissional (FORMOSINHO; NIZA, 2009) e que merece ser enfatizada pelo professor da universidade. De modo que, por trás das considerações apresentadas, o que se pode ter é a ausência de um diálogo mais objetivo. Portanto, a carência de um trabalho conjunto entre as escolas e a universidade produz um desconhecimento da realidade a ser experienciada (TARDIF, 2010). Embora 0 aceite do estagiário na escola seja algo que fique a critério da direção da escola e do professor de classe, isso não merece nenhum tratamento pontual, mesmo no âmbito da Diretoria de Ensino.

[...] nas escolas, o estágio funciona assim, o estagiário vai diretamente na escola; é poder do diretor aceitar ou não o estagiário, tá? Se ele achar que deve..., ele aceita e faz uma avaliação da escola e os limites que ele tem..., e no máximo dois estagiários por turma, para não ficar muita gente, né? E ele aceita, [...] até bem pouco tempo, ninguém ligava muito pra isso, sabe? (Supervisora da Diretoria de Ensino)

A fala da supervisora apenas confirma que a direção da escola é a responsável pela aceitação ou não dos estagiários, evidenciando novamente como ocorre a relação entre universidade e escola através de seus agentes (BORGES, 2008). Nesta direção, a coordenadora de Educação Física da Diretoria de Ensino também assinala que: 
Eu, até dois anos atrás, quando não tinha esse contato com o (professor da universidade)..., é... a gente já se conhecia aí de curso, né? A gente começou a conversar um pouco sobre a formação dos alunos..., até esse momento eu não sabia como acontecia o estágio na escola, né? [...]Então algumas pessoas me procuravam aqui na Diretoria de Ensino..., mas eu não tinha um envolvimento com o estágio, né? Eu sabia que ocorria porque eu escutava dos professores... ah, eu tenho estagiário lá que tá me ajudando..., estagiário, estagiário, mas eu não... não... participava dessa tramitação de estágio, né? (Coordenadora de Educação Física)

Assim, o que se encontra é que o estágio curricular é algo que não está entre as prioridades de uma política docente de formação de professores. Ele existe, ocupa um espaço, mas o seu lugar não é conhecido, podendo-se dizer que não está entre as prioridades (BENITES, 2012). As orientações dadas pela lei 11778/2008 sobre o estágio na prescrição dos direitos e deveres da escola e da universidade não são suficientes, ficando superficiais e genéricas.

\subsection{Parceria entre Universidade e Escola}

Na ausência de orientações mais amplas, acaba ficando para o diretor da escola estabelecer regras para o desenvolvimento do estágio:

Eu acho que... eu deixo assim muito claro no começo... na nossa conversa, o que tem que ser feito..., como que tem que funcionar..., como que é que é o estágio... Se a pessoa achar que não dá..., então procura outra escola que não tenha essa exigência, e fica livre, entendeu? [...] Tem algumas, alguns critérios..., se não funcionar, eu sou muito honesta de chegar e falar... ó, você não tá correspondendo com isso..., com isso..., com isso..., nós combinamos..., você não tá cumprindo..., dá pra melhorar..., não dá..., o que a gente pode fazer..., se a pessoa não se encaixa, não se enquadra, não se encaixa, não se adapta, então não tem por que continuar, entendeu? (Diretora 1)

Dessa forma, percebe-se que, dependendo da escola, a diretora, apesar de não ter uma orientação oficial, toma a iniciativa de estabelecer algumas regras para o estágio, deixando nas entrelinhas que pode não haver um acompanhamento mais de perto do professor da universidade ou que a sua presença não seja tão frequente. Já para o professor da escola, a parceria ocorre pela camaradagem:

[...] então através dessa amizade (...) que se criou a partir da especialização, é... a gente manteve esse contato, né? E a gente tem feito algumas coisas juntos, é... principalmente com essa ideia de abrir a porta da escola para as pessoas de lá, né? (...) Então a parceria é nesse sentido, né, de abrir a porta da escola pra universidade vir aqui, né? De vez em quando eu sou convidado pra falar lá no curso de Educação Física, né? Então tem um intercâmbio mais por conta da amizade, né, que foi criado, não tem nenhum vínculo, oficial, né, um convênio escrito, tal, é mais por conta da amizade, e da confiança que você tem nas pessoas de lá, e as pessoas... e... aparentemente as pessoas confiam em mim também..., então, me convidam pra ir lá, vêm uns alunos aqui, então é nesse sentido, não é nada oficial. (Professor1)

Assim, através desse depoimento, vai ficando claro que a relação entre professores da universidade e professores da escola ocorre pela camaradagem (BENITES, 2012), envolvendo relações interpessoais. No relato do professor universitário, também é evidenciado que: 
[...] uma forma de você aproximar dele é você convidar um professor para fazer uma palestra num dia de aula com seus alunos, por exemplo, né? Ele traz o conhecimento lá dele, e a gente faz essa conexão, e é uma forma deles se sentirem também vistos, né? [...] Então aí você acaba dando ferramentas pra ele, incentiva... olha, é interessante publicar, disponibiliza locais de publicação, um deles, por exemplo, é vir lá e falar sobre o seu trabalho, na sala de aula, aí os alunos se interessam, outros complementam, né? (Professor Universidade).

Como se pode notar, as relações ocorrem de ambos os lados, no sentido de se abrir portas, mas não se observa um projeto de estágio em desenvolvimento (BENITES, 2012), pois o estágio pode ser visto apenas como uma atividade a ser cumprida a cada ano.

O professor da universidade assinala também que:

Todo o início de semestre, eu tenho que voltar pra cada uma dessas escolas falar novamente pra cada uma dessas pessoas, convencê-las novamente da importância do estágio, do que a gente vai estar desenvolvendo, apesar deles me conhecerem... tudo mais, mas pode ter mudado a gestão, entendeu? Mudou a gestão, tem que começar do zero novamente, não é uma coisa assim que todo mundo já sabe, todo mundo já conhece, e todo mundo já disponibiliza isso pra você..., isso deveria ser o ideal, [...] nós sabemos que a universidade é nossa parceira, [...] estamos abertos pra isso, não precisa vir falar com diretor, com professor, com ninguém, né? (Professor Universidade)

Há, portanto, um trabalho de Sísifo de todo ano retomar as parcerias com a escola, pois, se de um lado há a camaradagem, de outro nem sempre se tem uma colaboração consolidada. A parceria entre universidade e escola implica na interação de duas instituiçõos que se inter-relacionam e produzem múltiplos conhecimentos (AZEVEDO, 2009). De forma que, se 0 trabalho de parceria não envolver uma via de mão dupla, não se avança nesse processo (SARTI, 2009).

\section{OS DESAFIOS DA RELAÇÃO ENTRE UNIVERSIDADE E ESCOLA NO ESTÁGIO CURRICULAR}

Os dados apresentados nos quatro eixos revelaram fragilidades em relação à parceria universidade e escola, evidenciando fragmentos de um modelo acadêmico de formação em que os pesquisadores e formadores universitários produzem e controlam os saberes da formação, enquanto que os professores das escolas são os "aplicadores" desses saberes (BORGES, 2008) ou os auxiliares na aprendizagem da docência, podendo ceder o espaço da sala de aula. Assim, o primeiro desafio que emerge está na relação vertical que se estabelece com a escola, evidenciado no depoimento do Professor 1: "[...] é...principalmente com essa ideia de abrir a porta da escola, para as pessoas de lá, né? [...]. Então a parceria é nesse sentido, né, de abrir a porta da escola pra universidade vir aqui, né?". Da mesma forma se encontra um segundo desafio nos vestígios de uma formação artesanal, em que a maioria dos estagiários "[...] fica realmente só na observação" (Professor 1), observando os mais experientes (TARDIF, 2013) e aprendendo pela tentativa-erro (RUGIU, 1998).

Essa parceria revela também um terceiro desafio, no qual o professor da escola, ao se deparar com a situação de acolher e auxiliar o estagiário, expõe em seu discurso uma ação pautada na boa vontade, "um intercâmbio mais por conta da amizade" (Professor 1), uma vez que ele não foi (in)formado sobre o seu papel no contexto do estágio supervisionado (BENITES, 2012), pois "não é nada oficial" (Professor 1). 
Sarti (2009) aponta como desafio a falta de um trabalho articulado entre as instituições responsáveis pela formação dos professores e as escolas que recebem os estagiários. Esta perspectiva é exposta na forma de um quarto desafio pela Diretora 2 ao assinalar que "Às vezes tem professor que me liga, a gente conversa antes, às vezes não liga, o aluno vem me procurar", chamando a atenção para necessidade de promover a integração entre universidade e escola (AZEVEDO, 2009), bem como na exposição do Professor 2, de se ter "[...] um compromisso tanto da universidade como da escola..., não é simplesmente mandar um ofício, você fala: tô enviando tantos estagiários", pois estes, na maioria das vezes, "[...] não têm clareza da dinâmica do estágio, do funcionamento institucional da escola, o que farão nela, qual seu papel, os limites e o alcance de sua atuação" (BARREIRO; GEBRAN, 2010, p.65).

Os desafios localizados, entre outros, evidenciam a compreensão dos participantes do estudo em relação ao estágio supervisionado, bem como têm merecido o aprofundamento de estudos no sentido de se constituir uma estrada de mão dupla entre universidade e escola, exigindo-se uma relação mais horizontal e uma cultura de colaboração.

Pimenta e Lima (2011) sugerem projetos de estágio, abrangendo as dimensões: pedagógica, referente ao currículo, alunos, práticas pedagógicas; organizacional, envolvendo questões administrativas e financeiras; profissional, relativa à formação continuada, bem como às condições de exercício docente, e social, envolvendo a comunidade. A ideia de projeto aparece relacionada com a questão educativa e o trabalho conjunto, bem como os estágios, a partir dessa perspectiva, supõem o compromisso de realizar projetos significativos para uma escola de melhor qualidade. Como proposto em Ribeirão Preto, na USP, as atividades de estágios do curso de Pedagogia são acompanhadas na própria escola, e o seu conteúdo é discutido tanto durante o horário de aula, com as disciplinas-estágio, quanto fora desse horário (CORREA, 2009). Nessa experiência, há um modelo diferenciado, uma vez que conta com contrato remunerado de educadores selecionados para auxiliar nas tarefas relativas ao estágio.

Em Rio Claro, na UNESP, há outro trabalho de formação docente iniciado em 2006, propondo a parceria entre o Departamento de Educação e a Secretaria Municipal de Educação, envolvendo 24 escolas de ensino fundamental. A partir do interesse das escolas, foi gerada uma lista de instituições parceiras, para as quais os alunos-estagiários são encaminhados para a realização dos estágios supervisionados. Durante o período de permanência na escola, o aluno deverá buscar informações sobre aspectos que chamam a atenção, como a relação entre professor e aluno e dos sujeitos com os materiais escolares etc. Nos meses em que os estagiários observam as aulas, os professores das escolas são convidados a frequentar um grupo na universidade coordenado pela docente responsável, tendo como eixo as experiências que realizam com os estagiários. Assim, há uma articulação, nesse trabalho formativo, com a universidade, na qual a intenção é a de que os professores partilhem, com os estudantes, as suas impressões, saberes, dúvidas e práticas ligadas ao trabalho docente (SARTI, 2009).

Na Educação Física, há a iniciativa de formação de professores-colaboradores por meio de curso de extensão, com o propósito de discutir e refletir sobre elementos da formação, bem como sobre a responsabilidade pela formação dos futuros professores, enfatizando a importância do processo de colaboração no momento do estágio. Tal proposta foi possível em função de parceria com a Prefeitura Municipal de Rio Claro, momento em que se evidenciou o papel do professor como corresponsável pela formação dos futuros professores, colocando 
em relevo o compromisso com relação ao ensino de Educação Física no momento do estágio (BENITES; CYRINO; SOUZANETO, 2013).

Em São Paulo, na UNIFESP, há o programa de Residência Pedagógica, um modelo de formação diferenciado do curso de Pedagogia, implantado em 2006, propondo uma vinculação entre formação inicial e continuada por meio da imersão dos estagiários

\footnotetext{
[...] em vivências sistemáticas e temporárias nas práticas pedagógicas de docentes e gestores escolares profissionais, acompanhadas pela orientação de um preceptor (docente da universidade) e de professores e gestores das escolas-campo considerados como colaboradores no processo de formação inicial. (GIGLIO, 2010, p. 376)
}

Nesse programa, "as escolas, em especial as pertencentes às escolas públicas de ensino, são os principais campos de aprendizagem prática das instituições formadoras por serem lugares onde os saberes profissionais se desenvolvem" (GIGLIO, 2010, p. 380).

Assim sendo, Benites (2012, p.152) nos propõe a necessidade de se constituir uma pedagogia do estágio para "[...] fundamentar, ordenar, sistematizar determinado conteúdo/atividade, além de refletir sobre o mesmo e posicionar-se frente a um conjunto de habilidades, no qual se pode pautar para agir dentro do processo educativo".

\section{ALGUMAS CONSIDERAÇÕES: A PROFISSIONALIZAÇÃO DO ENSINO COMO PROPOSTA}

A parceria entre universidade e escola é crucial para o desenvolvimento dos estágios supervisionados na formação de professores, pois ela indica ou não a relação de reciprocidade que pode haver entre duas instituições formadoras e produtoras de conhecimentos.

A pesquisa trouxe à tona que é preciso falar de dentro dessa relação que envolve universidade e escola, pois há no Brasil um discurso muito forte sobre a formação de professores (universidade e escola), mas não há um discurso consistente da formação de professores (universidade e escola) que emirja do interior das práticas pedagógicas e que coloque no centro desse processo o trabalho docente. Não temos analisado as nossas práticas de (o) ensino com o cuidado que elas merecem, apesar das experiências isoladas. De modo que muitos temas começam a ser uma paisagem comum no cenário da docência, não se dando a devida atenção. A aprendizagem da docência tem ficado circunscrita à observação e tentativa-erro, podendo essa experiência de ensino ser planejada ou não. Portanto, a idade do ensino como vocação ou como ofício habita esse espaço.

Os participantes deste estudo não são bons nem ruins, mas pessoas em formação e autoformação, revelando que o grande desafio consiste em transitar de um modelo de formação artesanal ou aplicacionista para um modelo de formação profissional que leve em consideração o desenvolvimento de uma cultura profissional e os saberes docentes.

Para avançar é preciso um movimento recíproco em que a profissão docente, aquilo que o professor é e faz, esteja dentro da universidade, e esta, por sua vez, esteja dentro da escola, de modo a legitimar os saberes da ação pedagógica.

Os dados revelaram que há predisposição para que as coisas possam ser feitas de forma diferente, desde que haja diálogo entre os agentes da universidade e da escola, uma vez que são protagonistas nos processos formativos dos futuros professores. 


\section{REFERÊNCIAS}

ALVEZ-MAZZOTTI, Alda J.; GEWANDSZNAJDER, Fernando.O Método nas Ciências Naturais e Sociais: pesquisa qualitativa e quantitativa. São Paulo: Pioneira Thomson Learning, 2001.

AZEVEDO, Maria Antonia R. Os Saberes de Orientação dos Professores Formadores: desafios para ações tutoriais emancipatórias. $260 \mathrm{f}$. Tese (Doutorado). - Faculdade de Educação da Universidade de São Paulo, São Paulo, 2009.

BARREIRO, Iraíde M. F.; GEBRAN, Raimunda. A Prática de Ensino e Estágio Supervisionado na formação de professores. 2. Reimp.. São Paulo: Avercamp, 2010.

BENITES, Larissa C. 0 professor-colaborador no estágio Curricular Supervisionado em Educação Física: Perfil, Papel e Potencialidades. 184 f. Tese (Doutorado) - Programa de PósGraduação em Ciências da Motricidade, Instituto de Biociências, Campus de Rio Claro, Universidade Estadual Paulista Julio de Mesquita Filho, Rio Claro, 2012.

BENITES, Larissa C.; CYRINO, Marina; SOUZA NETO, Samuel. Estágio Curricular Supervisionado: a formação do professor-colaborador. Olh@res, Guarulhos, v. 1, n. 1, p. 116-140, maio 2013.

BORGES, Cecilia. A formação docente em Educação Física em Quebec: saberes, espaços, culturas e agentes. In: TRAVERSINI, C. (org.).Trajetória e processos de ensinar e aprender: práticas e didáticas. Porto Alegre: EDIPUCSRS, 2008. p. 147-174.

BRASIL. Presidência da República. Casa Civil. Lei no. 11.788, de 25 de setembro de 2008: dispõe sobre o estágio de estudantes. Diário Oficial da União, Brasília, DF, Seção 1, p. 3, 2008.

CONTRERAS, Jose. A autonomia de Professores. São Paulo: Cortez, 2002.

CORREA, Bianca C. Experiências de Estágio em um curso de pedagogia: vivências e desafios em busca de uma formação de qualidade. In: CONGRESSO INTERNACIONAL CIDInE, 2, 2009. Anais... Novos contextos de formação, pesquisa e mediação. Aveiro, 2009.

FORMOSINHO, João; NIZA, Sergio. Iniciação à prática profissional de formação inicial de professores. In: FORMOSINHO, João (coord.). Formação de Professores. Porto: Porto Editora, 2009. p. 119-139.

GAUTHIER, Clemont et al. Apresentação - Ensinar: Ofício Estável, Identidade Profissional Vacilante. In:__. Por uma teoria da pedagogia: Pesquisas Contemporâneas sobre o saber docente. ljuí: Unijuí, 1998. p. 19-37.

GIGLIO, Célia M. B. Residência Pedagógica como diálogo permanente entre a formação inicial e continuada de professores. In: DALBEN, A. I. L. de F. et al. Convergências e tensões no campo da formação e do trabalho docente.Belo Horizonte: Autêntica, 2010.

HOLMES GROUP. Tomorrow's teachers: a report of the Holmes Group. East Lansing, MI, 1986.

LÜDKE, Menga; ANDRÉ, Marli E. D. A. Pesquisa em Educação: abordagens qualitativas. 6.ed. São Paulo: EPU, 2001.

MOURA, Manoel O. (coord.). 0 estágio na formação compartilhada do professor: retratos de uma experiência. São Paulo: FEUSP, 1999.

PIMENTA, Selma G.; LIMA, Maria Socorro L. Estágio e Docência. 6. ed. São Paulo: Cortez, 2011 (Coleção Docência em Formação - Série Saberes Pedagógicos).

PIMENTA, Selma G. 0 Estágio na Formação de Professores: unidade teoria e prática? 7.ed. São Paulo: Cortez, 2006.

RUGIU, Antonio S. A Nostalgia do Mestre Artesão. Campinas, SP: Autores Associados, 1998.

(Coleção Memória da Educação). 
SARTI, Flavia Medeiros. Parceria Intergeracional e Formação Docente. Educação em Revista, Belo Horizonte, v. 25, n.2,p. 133-152, ago. 2009.

SARTI, Flávia. M. O triângulo da formação docente: seus jogadores e configurações. Educação e Pesquisa, São Paulo, v.38, n.2, p.323-338, 2012.

TARDIF, Maurice. A profissionalização do ensino passados trinta anos: dois passos para a frente, três para trás. Educação e Sociedade, Campinas, SP, v.34, n.123, p. 551-571, abr./jun. 2013.

TARDIF, Maurice. Saberes Docentes e Formação Profissional. 10.ed.. Petrópolis, RJ: Vozes, 2010.

TARDIF, Maurice; RAYMOND, D. Saberes, tempo e aprendizagem do trabalho no magistério.

Educação \& Sociedade, Campinas, v. 21, n. 73, p. 209-244, dez.2000. 